\title{
A case of EDTA-dependent pseudothrombocytopenia: simple recognition of an underdiagnosed and misleading phenomenon
}

\author{
Michael Nagler*, Peter Keller, Daniel Siegrist and Lorenzo Alberio
}

\begin{abstract}
Background: EDTA-dependent pseudothrombocytopenia (EDTA-PTCP) is a common laboratory phenomenon with a prevalence ranging from $0.1-2 \%$ in hospitalized patients to $15-17 \%$ in outpatients evaluated for isolated thrombocytopenia. Despite its harmlessness, EDTA-PTCP frequently leads to time-consuming, costly and even invasive diagnostic investigations. EDTA-PTCP is often overlooked because blood smears are not evaluated visually in routine practice and histograms as well as warning flags of hematology analyzers are not interpreted correctly. Nonetheless, EDTA-PTCP may be diagnosed easily even by general practitioners without any experiences in blood film examinations. This is the first report illustrating the typical patterns of a platelet (PLT) and white blood cell (WBC) histograms of hematology analyzers.

Case presentation: A 37-year-old female patient of Caucasian origin was referred with suspected acute leukemia and the crew of the emergency unit arranged extensive investigations for work-up. However, examination of EDTA blood sample revealed atypical lymphocytes and an isolated thrombocytopenia together with typical patterns of WBC and PLT histograms: a serrated curve of the platelet histogram and a peculiar peak on the left side of the WBC histogram. EDTA-PTCP was confirmed by a normal platelet count when examining citrated blood.
\end{abstract}

Conclusion: Awareness of typical PLT and WBC patterns may alert to the presence of EDTA-PTCP in routine laboratory practice helping to avoid unnecessary investigations and over-treatment.

Keywords: Thrombocytopenia, Laboratory hematology, Hematology analyzers

\section{Background}

EDTA-dependent pseudothrombocytopenia (EDTA-PTCP) is a common laboratory phenomenon. Its prevalence is reported to vary between $0.1-2 \%$ among hospitalized patients [1-3] and $15-17 \%$ in outpatients evaluated for isolated thrombocytopenia $[4,5]$. In contrast to serious and potential life-threatening causes of thrombocytopenia [6], EDTA-PTCP is solely an in vitro effect without any clinical relevance [7]. Cation chelation by EDTA leads to a conformational change of the platelet membrane GPIIbIIIa complex unmasking a cryptic epitope, that becomes accessible for autoantibodies [8]. Antibodies are predominantly of IgG type but act as cold agglutinins that react with platelets in vitro. Hematology analyzers count the

\footnotetext{
* Correspondence: michael.nagler@insel.ch

Department of Hematology and Central Hematology Laboratory, Inselspital University Hospital and University of Berne, $\mathrm{CH}-3010$ Berne, Switzerland
}

resulting platelet clumps as single giant platelets or as small lymphocytes in the white blood cell gate and indicate thrombocytopenia. Despite its harmlessness, EDTAPTCP may generate significant costs and discomfort to the patient due to needless diagnostic testing, unnecessary transfusions and even withhold of emergency treatments [8-12]. Often, EDTA-PTCP remains unnoticed because blood smears are not routinely evaluated by visual inspection and warning flags as well as histograms of hematology analyzers are not interpreted correctly. However, EDTA-PTCP may be diagnosed easily even by general practitioners without any experiences in blood film examinations as aggregated platelets lead to typical changes of platelet (Figure 1; PLT) and white blood cell histograms (Figure 1; WBC) [1]. To the best of our knowledge, this typical pattern of the platelet histogram has not been published so far. 


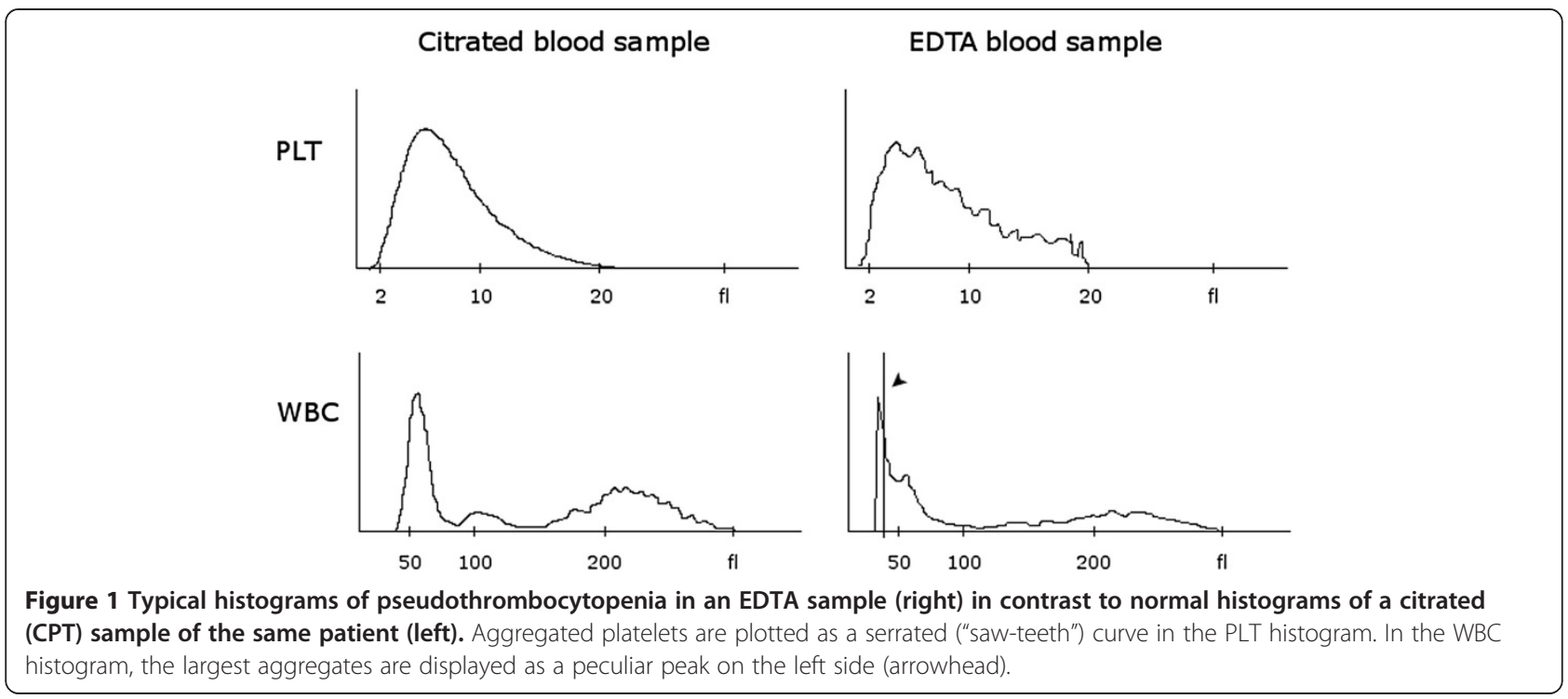

Visual evaluation of blood smears is regarded as gold standard for detection of EDTA-PTCP, but only a limited amount of smears will be performed in routine laboratories. A simpler approach for detection of EDTA-PTCP is to inspect the histograms and flags of hematology analyzers. Although proper diagnostic accuracy studies have not been done and previous investigations using former models of hematology analyzer suggest some false-positive and false-negative results [1,13], EDTA-PTCP is expected to be diagnosed correctly in most cases by this approach $[8,14]$. In our practice, we visually evaluate blood smears in all cases with new or unexpected thrombocytopenia below $70 \times 10^{6} / \mu \mathrm{l}$, and in cases with the typical histogram patterns or the respective flags of the hematology analyzer.

Which strategies can be then applied to determine the correct platelet count in daily practice? Several alternative anticoagulants have been investigated, but most of them are either not applicable to current hematology analyzers, or may induce pseudothrombocytopenia by themselves [8]. In fact, besides EDTA, pseudothrombocytopenia was also recognised in samples anticoagulated with oxalate, heparin, and hirudin and even citrate $[15,16]$. This in vitro phenomenon was not observed in samples anticoagulated with mixtures of EDTA and aminoglycosides [17,18], with magnesium salt [19] and with the CPT mixture (citrate $17 \mathrm{mmol} / \mathrm{l}$, pyridoxal 5 '-phosphate $11.3 \mathrm{mmol} / \mathrm{l}$ and Tris $24.76 \mathrm{mmol} / \mathrm{l})[8,18,20]$. It is reported, that immediate processing of the blood samples and collection of the samples in pre-warmed tubes reduces the presence of platelet aggregates [7]. However, this manoeuvre will be possible in special settings only. In our laboratory if platelet aggregates are found, we confirm EDTA-PTCP and assess the correct

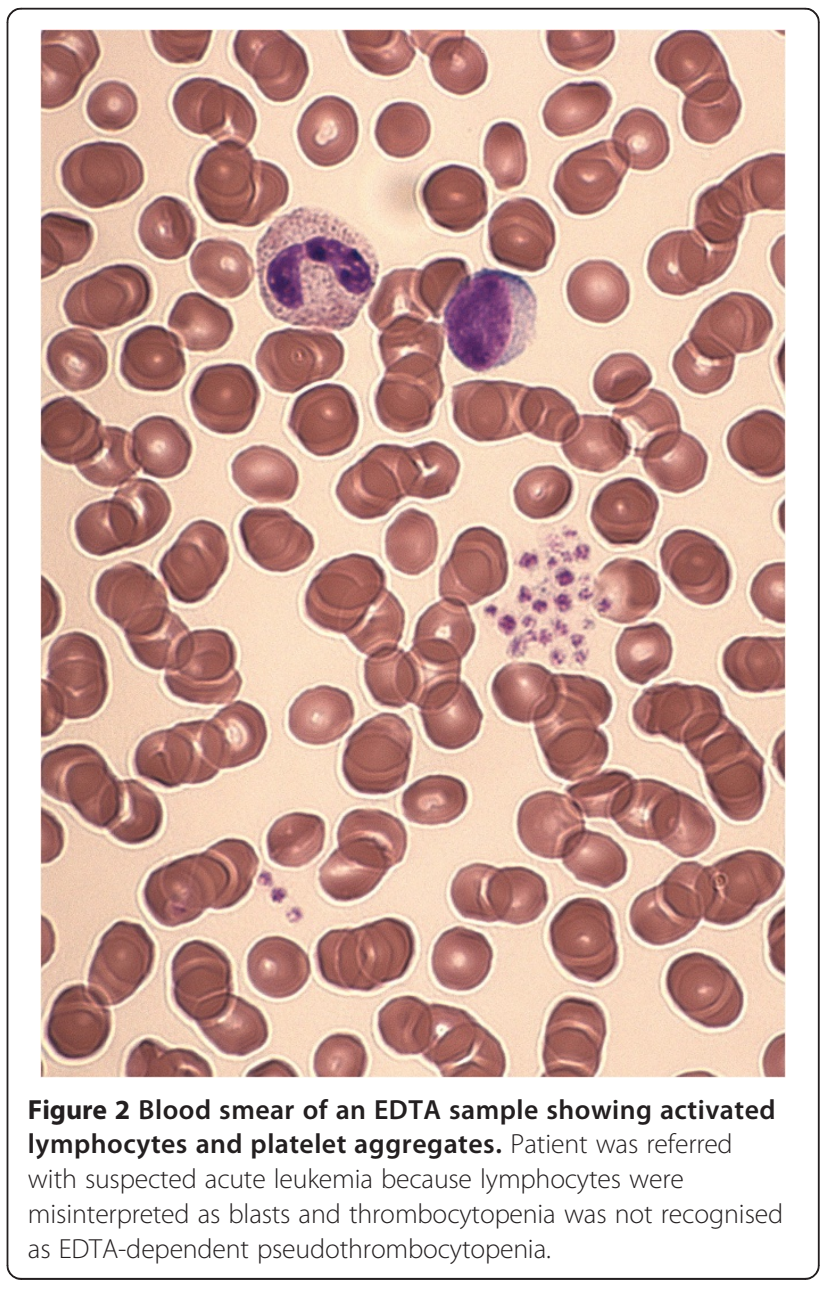


platelet count by obtaining a new sample using $\mathrm{CPT}$ as anticoagulant.

\section{Case presentation}

A 37-year-old female patient of caucasian origin was referred from a regional hospital with suspected acute leukemia. The referring physician reported on fever, cough, severe thrombocytopenia and irregular cells in the blood smear. Emergency unit crew arranged extensive laboratory investigations, ordered a CT scan, asked for bone marrow biopsy, and reserved a platelet concentrate. Examination of EDTA blood by an automated hematology analyzer (Coulter Counter LH750, Beckman-Coulter Inc., Nyon, Switzerland) showed an isolated thrombocytopenia $\left(38 \times 10^{6} / \mu \mathrm{l}\right)$ as well as typical patterns of platelet and WBC histograms. The aggregated platelets lead to an serrated ("saw-teeth") curve of the platelet histogram (Figure 1) and the largest platelet aggregates are plotted as a peculiar peak on the left side of the WBC histogram (Figure 1; arrowhead). Furthermore, hematology analyzer reported on the following flags: "platelet clumps" and "giant platelets". Visual inspection of the blood smear revealed activated lymphocytes and platelet aggregates (Figure 2). EDTA-dependent pseudothrombocytopenia (EDTA-PTCP) was confirmed by a normal platelet count when examining CPT-anticoagulated blood $(173 \times 106 / \mu \mathrm{l})$. Due to normalisation of PLT, no blood smear of the citrated sample was performed. Review of previous laboratory tests with the family physician revealed normal PLT values. Thus, activated lymphocytes as well as EDTAPTCP were interpreted as secondary to upper airway infection $[8,21]$.

\section{Conclusions}

In conclusion, this case illustrates typical patterns of platelet and WBC histograms on automated hematology analyzers in EDTA-PTCP (Figure 1). Awareness of these patterns may alert to the presence of EDTA-PTCP in routine clinical practice. This may help physicians as well as laboratory personnel to be aware of EDTA-PTCP and to prevent unnecessary investigations as well as over-treatment.

\section{Consent}

Written informed consent was obtained from the patient for publication of this Case report and any accompanying images. A copy of the written consent is available for review by the Editor of this journal.

\section{Abbreviations}

EDTA-PTCP: EDTA-dependent pseudothrombocytopenia; WBC: White blood cell.

\section{Competing interests}

The authors declare that they have no competing interests.

\section{Authors' contributions}

MN and DS looked after the patient, conducted the blood smear and interpreted the histogram of the hematology analyzer. PK and LA supervised hematologists on duty. MN wrote the first draw of the manuscript. All authors revised the manuscript. All authors read and approved the final manuscript.

Received: 25 October 2013 Accepted: 17 April 2014

Published: 1 May 2014

\section{References}

1. Bartels PC, Schoorl M, Lombarts AJ: Screening for EDTA-dependent deviations in platelet counts and abnormalities in platelet distribution histograms in pseudothrombocytopenia. Scand J Clin Lab Invest 1997, 57(7):629-636.

2. Vicari A, Banfi G, Bonini PA: EDTA-dependent pseudothrombocytopaenia: a 12-month epidemiological study. Scand J Clin Lab Invest 1988, 48(6):537-542

3. Zandecki M, Genevieve F, Gerard J, Godon A: Spurious counts and spurious results on haematology analysers: a review. Part I: platelets. Int J Lab Hematol 2007, 29(1):4-20.

4. Cohen AM, Cycowitz Z, Mittelman M, Lewinski UH, Gardyn J: The incidence of pseudothrombocytopenia in automatic blood analyzers. Haematologia 2000, 30(2):117-121.

5. Silvestri F, Virgolini L, Savignano C, Zaja F, Velisig M, Baccarani M: Incidence and diagnosis of EDTA-dependent pseudothrombocytopenia in a consecutive outpatient population referred for isolated thrombocytopenia. Vox Sang 1995, 68(1):35-39.

6. Alberio L: My patient is thrombocytopenic! Is (s)he? Why? And what shall I do? A practical approach to thrombocytopenia. Hamostaseologie 2013, 33(2):83-94.

7. Bizzaro N: EDTA-dependent pseudothrombocytopenia: a clinical and epidemiological study of 112 cases, with 10-year follow-up. Am J Hematol 1995, 50(2):103-109.

8. Bizzaro N: Pseudothrombocytopenia. In Platelets. Volume. 3rd edition. Elsevier, Amsterdam: Academic Press; 2013:989-997.

9. Kocum TH, Katircibasi TM, Sezgin AT, Atalay H: An unusual cause of mismanagement in an acute myocardial infarction case: pseudothrombocytopenia. Am J Emerg Med 2008, 26(6):740 e741-742.

10. Lau LG, Chng WJ, Liu TC: Transfusion medicine illustrated. Unnecessary transfusions due to pseudothrombocytopenia. Transfusion 2004, 44(6):801.

11. Chia J, Hsia CC: Pseudothrombocytopenia. Blood 2011, 117(16):4168.

12. Payne BA, Pierre RV: Pseudothrombocytopenia: a laboratory artifact with potentially serious consequences. Mayo Clin Proc 1984, 59(2):123-125.

13. Cunningham VL, Brandt JT: Spurious thrombocytopenia due to EDTA-independent cold-reactive agglutinins. Am J Clin Pathol 1992, 97(3):359-362.

14. Wu W, Guo Y, Zhang L, Cui W, Li W, Zhang S: Clinical utility of automated platelet clump count in the screening for ethylene diamine tetraacetic acid-dependent pseudothrombocytopenia. Chin Med J 2011, 124(20):3353-3357.

15. Schrezenmeier H, Muller H, Gunsilius E, Heimpel H, Seifried E: Anticoagulantinduced pseudothrombocytopenia and pseudoleucocytosis. Thromb Haemost 1995, 73(3):506-513.

16. Robier C, Neubauer M, Sternad H, Rainer F: Hirudin-induced pseudothrombocytopenia in a patient with EDTA-dependent platelet aggregation: report of a new laboratory artefact. Int I Lab Hematol 2010, 32(4):452-453.

17. Sakurai S, Shiojima I, Tanigawa T, Nakahara K: Aminoglycosides prevent and dissociate the aggregation of platelets in patients with EDTA-dependent pseudothrombocytopenia. Br J Haematol 1997, 99(4):817-823.

18. Ozcelik F, Arslan E, Serdar MA, Yiginer O, Oztosun M, Kayadibi H, Kurt I: A useful method for the detection of ethylenediaminetetraacetic acid- and cold agglutinin-dependent pseudothrombocytopenia. Am J Med Sci 2012, 344(5):357-362.

19. Schuff-Werner P, Steiner M, Fenger S, Gross HJ, Bierlich A, Dreissiger K, Mannuss S, Siegert G, Bachem M, Kohlschein P: Effective estimation of correct platelet counts in pseudothrombocytopenia using an alternative 
anticoagulant based on magnesium salt. Br J Haematol 2013, 162(5):684-692.

20. Lippi U, Schinella M, Nicoli M, Modena N, Lippi G: EDTA-induced platelet aggregation can be avoided by a new anticoagulant also suitable for automated complete blood count. Haematologica 1990, 75(1):38-41.

21. Choe WH, Cho YU, Chae JD, Kim SH: Pseudothrombocytopenia or platelet clumping as a possible cause of low platelet count in patients with viral infection: a case series from single institution focusing on hepatitis $A$ virus infection. Int I Lab Hematol 2013, 35(1):70-76.

doi:10.1186/1472-6890-14-19

Cite this article as: Nagler et al: A case of EDTA-dependent pseudothrombocytopenia: simple recognition of an underdiagnosed and misleading phenomenon. BMC Clinical Pathology 2014 14:19.

\section{Submit your next manuscript to BioMed Central and take full advantage of:}

- Convenient online submission

- Thorough peer review

- No space constraints or color figure charges

- Immediate publication on acceptance

- Inclusion in PubMed, CAS, Scopus and Google Scholar

- Research which is freely available for redistribution 